\title{
US Men Discussing Prostate-Specific Antigen Tests With a Physician
}

Stephanie L. McFall, PbD

University of Texas Health Science Center, School of Public Health, San Antonio, Tex

\begin{abstract}
PURPOSE Informed decision making is recommended for prostate cancer screening. I wanted to examine demographic and screening-related factors associated with men's discussion of the advantages and disadvantages of prostate-specific antigen (PSA) tests with their physicians.
\end{abstract}

METHODS I used data from 2,184 men aged 50 years and older who reported a screening prostate-specific antigen (PSA) test in the 2000 National Health Interview Survey cancer control supplement. The dependent variable was discussion of the advantages and disadvantages of the test before it was conducted.

RESULTS Sixty-three percent of tested men reported a discussion in relation to their most recent PSA test. Discussion was more common for African American men and those with a usual source of care, and when the physician initiated the testing.

CONCLUSIONS Characteristics of the patient-physician relationship were more central to the discussion of risks and benefits than were patient attributes. Future research should examine what role practice setting and the physician-patient relationship play in a discussion of PSA testing and how to facilitate active involvement of patients in decision making.

Ann Fam Med 2006;4:433-436. DOI: 10.1370/afm.576.

\section{INTRODUCTION}

Thormed or shared decision making has been recommended for medical choices for which the supporting evidence is not conclusive and patient preferences are central. ${ }^{1-3}$ Whether to have prostate cancer screening is an example of such a decision. ${ }^{4}$ Professional organizations differ about whether to recommend prostate cancer screening but substantially agree that physicians should inform men about the benefits and risks of screening to help patients reach decisions suited to their preferences and values. ${ }^{5-9}$

Communication frameworks suggest that the likelihood and nature of discussions are shaped by characteristics of the physician, the patient, and such features of the interaction as setting. Some research has examined characteristics of physician and practice setting that influence participatory discussion in general..$^{10-12}$ For example, discussion is more likely with primary care physicians than other medical specialists and less likely in busy high-volume practices. ${ }^{11,12}$ Characteristics of the event have also been found to be important. Decisions viewed as routine may be discussed less frequently, and new patient management strategies, such as a new medication, may be discussed more frequently. Similarly, when considering an initial prostate-specific antigen (PSA) test, patient attributes, such as age, socioeconomic position, or risk, as perceived by physician or patient may also influence discussion. . $^{13,14}$

Many studies show that men lack knowledge of prostate cancer screening, including the advantages and disadvantages of the PSA test. ${ }^{15} \mathrm{~A}$ few studies have assessed the frequency of discussion of the PSA test. Chan et 
$\mathrm{al}^{16}$ reported that fewer than one half of 304 tested men reported discussing the advantages and disadvantages of the test. In a Veterans Affairs setting, Federman et a $1{ }^{17}$ reported that two thirds of tested men recalled having the test, and $47 \%$ reported discussing its advantages and disadvantages. These studies had small sample sizes and were conducted in specific clinics, which limit our ability to generalize. Given the emphasis placed on informed or shared decision making about prostate cancer screening, it is important to examine in a nationally representative sample of men the relative frequency of such discussions and those patient and screening event factors associated with them.

My purpose was to assess (1) the proportion of men screened with PSA tests who reported discussion of the test with their physicians and (2) respondent and screening event characteristics correlated with such discussions.

\section{METHODS}

Data were from the 2000 National Health Interview Survey (NHIS) cancer control supplement. ${ }^{18}$ The cancer control supplement is part of the adult interview.

One hallmark of the NHIS is in-person interviews conducted by highly trained Bureau of the Census interviewers. Although a responsible adult may answer questions about other family members, the detailed adult interviews are generally conducted with the selected respondent. Interviews are in English or Spanish. For the 2000 survey, the household response rate was $88.9 \%$, and it was $82.6 \%$ for the adult interview, for an overall response rate of $72.1 \%$.

The data were obtained from public use files maintained by the National Center for Health Statistics. The project was approved as exempt by the Committee for the Protection of Human Subjects, The University of Texas Health Science Center-Houston.

From 2,763 sampled men aged 50 years or older who reported ever having a PSA test, 195 men with prostate cancer and 384 whose PSA test was not for screening were excluded, resulting in a sample size of 2,184 . Discussions in the excluded cases may be related to disease monitoring or treatment decisions, as in watchful waiting.

\section{Measurement}

The discussion question, asked of men who reported a PSA test, was, "Did the doctor discuss the advantages and disadvantages of this test with you before doing it?"

Sociodemographic variables included age-group, race/ethnicity, marital status, education, and income. Access variables were usual source of health care and health insurance. Family history of prostate cancer was measured by a report of prostate cancer among biological father, brothers, or sons. Screening-related variables included the timing of the last test, the number of tests in the past 5 years, who first suggested the test (patient, physician, or other), and any PSA tests with abnormal findings. The specific categories for all variables are displayed in Table 1.

\begin{tabular}{|c|c|c|c|}
\hline Characteristics & Percent* & $n^{*}$ & $P$ Value \\
\hline Race/ethnicity & & & .024 \\
\hline Non-Hispanic white & 62.2 & 1,717 & \\
\hline African American & 73.8 & 228 & \\
\hline Hispanic & 62.5 & 192 & \\
\hline Other & 70.1 & 47 & \\
\hline Age category, years & & & .951 \\
\hline $50-64$ & 63.5 & 1,136 & \\
\hline $65-74$ & 63.5 & 656 & \\
\hline 75 or older & 62.6 & 392 & \\
\hline Marital status & & & .158 \\
\hline Not married & 60.4 & 677 & \\
\hline Married & 64.0 & 1,503 & \\
\hline Education & & & .740 \\
\hline Less than high school & 65.2 & 437 & \\
\hline $\begin{array}{l}\text { High school graduate/gen- } \\
\text { eral equivalency diploma }\end{array}$ & 62.4 & 588 & \\
\hline Some college & 63.2 & 1,138 & \\
\hline Usual source of care & & & $<.001$ \\
\hline No source & 37.9 & 79 & \\
\hline Regular source & 64.1 & 2,104 & \\
\hline Health insurance & & & .714 \\
\hline Medicare/other public & 64.1 & 1,132 & \\
\hline Private & 62.4 & 970 & \\
\hline None & 65.8 & 75 & \\
\hline Family history & & & .431 \\
\hline $\begin{array}{l}\text { No history of prostate } \\
\text { cancer }\end{array}$ & 63.6 & 2,037 & \\
\hline Family history & 59.8 & 147 & \\
\hline Initial suggestion for test & & & $<.001$ \\
\hline From physician & 66.6 & 1,697 & \\
\hline From patient or other & 59.8 & 474 & \\
\hline Recency of testing & & & $<.001$ \\
\hline Within past year & 65.9 & 1,475 & \\
\hline More than 1 year & 57.5 & 709 & \\
\hline $\begin{array}{l}\text { Any previous abnormal PSA } \\
\text { result }\end{array}$ & & & .239 \\
\hline Abnormal result & 68.5 & 132 & \\
\hline No abnormal result & 63.0 & 2,050 & \\
\hline Tests in past 5 years & & & .012 \\
\hline None & 52.5 & 79 & \\
\hline 1 & 57.4 & 574 & \\
\hline 2 & 65.9 & 342 & \\
\hline 3 or 4 & 64.4 & 327 & \\
\hline 5 or more & 67.9 & 786 & \\
\hline
\end{tabular}




\section{Analysis Plan}

Survey weights and procedures in Stata 8.0 were used to account for the complex sample design and to incorporate weights that provide nationally representative estimates. ${ }^{19}$ Relative to bivariate analyses, several variables were dropped, including education, age, marital status, and health insurance. Results of the logistic regression were presented as adjusted odds ratios and 95\% confidence intervals. The overall significance of multiple category variables such as race/ethnicity was assessed with a Wald $\chi^{2}$.

\section{RESULTS}

Overall, 63\% of tested men reported that their physician discussed the advantages and disadvantages of PSA tests before it was conducted. In Table 1 discussion of PSA tests is cross-tabulated with respondent and screening variables. Few respondent attributes were associated with discussion, however, African American men were more likely and men without a usual source of care were less likely to report a discussion. Men with a family history of prostate cancer were

\section{Table 2. Weighted Logistic Regression Predicting Discussion of Prostate-Specific Antigen Test: Adjusted Odds Ratios and 95\% Confidence Intervals}

\begin{tabular}{|c|c|c|}
\hline Variable & $\begin{array}{c}\text { Adjusted } \\
\text { Odds Ratio }\end{array}$ & $\begin{array}{l}95 \% \text { Confidence } \\
\text { Interval }\end{array}$ \\
\hline \multicolumn{3}{|l|}{ Race/ethnicity* } \\
\hline Non-Hispanic white & 1.00 & \\
\hline African American & 1.73 & $1.19-2.51$ \\
\hline Hispanic & 1.21 & $.82-1.78$ \\
\hline Other & 1.12 & $.54-2.32$ \\
\hline \multicolumn{3}{|l|}{ Usual source of care ${ }^{\dagger}$} \\
\hline No & 1.00 & \\
\hline Yes & 2.43 & $1.39-4.24$ \\
\hline \multicolumn{3}{|l|}{ Family history } \\
\hline No & 1.00 & \\
\hline Yes & .89 & $.59-1.34$ \\
\hline \multicolumn{3}{|l|}{ Initial suggestion ${ }^{\ddagger}$} \\
\hline Physician & 1.77 & $1.40-2.23$ \\
\hline Other & 1.00 & \\
\hline \multicolumn{3}{|l|}{ Timing } \\
\hline Within past year & 1.18 & $.93-1.50$ \\
\hline More than 1 year & 1.00 & \\
\hline Number tests in $5 \mathrm{y}$ & 1.06 & $1.00-1.44$ \\
\hline \multicolumn{3}{|l|}{ Any abnormal result } \\
\hline Yes & 1.05 & $.69-1.60$ \\
\hline None & 1.00 & \\
\hline $\begin{array}{l}* P<.05 \\
\dagger P<.01 \\
\ddagger P<.001\end{array}$ & & \\
\hline
\end{tabular}

less likely to report discussion, though this relationship was not significant.

Several screening-related variables were associated with a discussion. Discussions were more likely in men who had more tests in the past 5 years. Men who reported a discussion had 3.2 tests in the past 5 years vs 2.8 tests for those with no discussion $(t=3.64 ; P$ $<.001)$. Discussion was more likely when a physician introduced the initial suggestion for a test or when the test was within the past year. Having had abnormal PSA results with a previous test was not related to discussion.

Because a discussion might be more likely with an initial test, I contrasted the reports of men who had 1 test in the past 5 years and reported a test in the past year with reports of all other screened men. These men were more likely to be having an initial test. Discussion was reported by $58.6 \%$ of the initial test group and by $63.9 \%$ of the other screened men. This difference is not statistically significant $(P=.131)$.

There was substantial overlap between the results of bivariate analyses and the logistic regression analysis displayed in Table 2. The strongest relationships with discussion, all positive, were seen for physician suggestion of the test, having a usual source of care, and African American race. The screening variables of having a test within the past year and number of tests were not significantly associated with discussion when controlling for the other variables shown in Table 2.

\section{DISCUSSION}

About $60 \%$ of men using PSA testing for prostate cancer screening discussed benefits and disadvantages with physicians before their PSA tests. Discussions were more likely in this nationally representative sample than in Veterans Affairs and primary care samples in specific limited locations. ${ }^{16,17}$ The converse view is more than one third of men who had PSA testing did not discuss the risks and benefits that could help them make informed decisions about screening. Because of the question sequence, we cannot pinpoint the frequency of discussion among untested men. Discussion is unlikely among the $28 \%$ of men who reported never having heard of PSA tests. ${ }^{20}$

A major strength of the study is its use of data from a nationally representative sample with a relatively high response rate. In contrast, studies using local clinic samples will have more representation bias and a limited ability to generalize findings to other populations. This study also has shortcomings. The restriction of the sample to men receiving screening tests may enhance the salience of the event, ${ }^{17}$ but men's recall of a discussion may not be accurate, particularly about the timing of dis- 
cussions. Thus, some of the difference in rates of discussion by men who had multiple PSA tests compared with those who had a single test may result from misattributing a past discussion to the most recent test. Similarly, the higher rate of discussion by men with a test in the past year may also be influenced by the greater ease of recalling recent events. The NHIS data also do not permit a detailed examination of the important dimension of the content of discussions. Detailed questions asking whether specific topics were talked about could result in fewer men stating that discussions of risks and benefits occurred. Finally, the data were collected in 2000, when there was less public attention concerning the importance of informed decision making about prostate cancer screening. It will be important in future research to examine trends in the relative frequency of discussion of advantages and disadvantages of prostate cancer screening. Unfortunately, the cancer control supplement in the 2005 NHIS does not include questions about discussion of the test with a physician.

Discussions were more likely when the physician suggested the test and for African American men. The impact of race, but not education, is interesting and suggests that physicians are attuned to the heightened risk and impact of prostate cancer for African American men and are addressing prostate cancer screening in office visits with them. That is, discussion is not more likely with more educated men. Participatory mechanisms such as discussion are more likely in uncertain or high-risk situations than for routine transactions. ${ }^{10,11}$ This finding is also consistent with studies that found physicians are more likely to discuss the PSA test when they are intending to order it. ${ }^{21}$

Characteristics of the patient-physician relationship are more central to the discussion of the test's advantages and disadvantages than are patient characteristics. It is noteworthy that a discussion was highly unlikely for the small group of tested men who did not have a usual source of health care. Because men with no regular source of care may be screened in special events, eg, health fairs, plans for such events should build in opportunities to learn about the benefits and risks of the PSA test.

Future research on discussion of PSA testing should examine the role of practice setting and the physician-patient relationship and how to facilitate active involvement of patients in decision making.

To read or post commentaries in response to this article, see it online at http://www.annfammed.org/cgi/content/full/4/5/433.

Key words: Prostate cancer/screening; prostate-specific antigen; patient-physician communication; decision making; health surveys, informed consent

Submitted October 7, 2005; submitted, revised, January 23, 2006; accepted January 30, 2006.

\section{References}

1. Briss P, Rimer B, Reilley $B$, et al. Promoting informed decisions about cancer screening in communities and healthcare systems. Am J Prev Med. 2004;26:67-80.

2. Becker DM, DeMong LK, Kaplan P, et al. Anticoagulation therapy and primary care internal medicine: a nurse practitioner model for combined clinical science. J Gen Intern Med. 1994;9:525-527.

3. Sheridan SL, Harris RP, Woolf SH. Shared decision making about screening and chemoprevention. a suggested approach from the U.S. Preventive Services Task Force. Am J Prev Med. 2004;26:56-66.

4. Barry MJ. Health decision aids to facilitate shared decision making in office practice. Ann Intern Med. 2002;136:127-135.

5. Prostate-specific antigen (PSA) best practice policy. American Urological Association (AUA). Oncology (Williston Park). 2000;14:267272, 277-268, 280 passim.

6. Ferrini R, Woolf SH. American College of Preventive Medicine practice policy. Screening for prostate cancer in American men. Am J Prev Med. 1998;15:81-84.

7. Harris R, Lohr KN. Screening for prostate cancer: an update of the evidence for the U.S. Preventive Services Task Force. Ann Intern Med. 2002;137:917-929.

8. Smith RA, Mettlin CJ, Davis KJ, Eyre H. American Cancer Society guidelines for the early detection of cancer. CA Cancer J Clin. 2000;50:34-49.

9. Zoorob R, Anderson R, Cefalu C, Sidani M. Cancer screening guidelines. Am Fam Physician. 2001;63:1101-1112.

10. Braddock $\mathrm{CH}$, 3rd, Fihn SD, Levinson W, Jonsen AR, Pearlman RA. How doctors and patients discuss routine clinical decisions. Informed decision making in the outpatient setting. J Gen Intern Med. 1997;12:339-345.

11. Gotler RS, Flocke SA, Goodwin MA, et al. Facilitating participatory decision-making: what happens in real-world community practice? Med Care. 2000;38:1200-1209.

12. Kaplan SH, Greenfield S, Gandek B, Rogers WH, Ware JE, Jr. Characteristics of physicians with participatory decision-making styles. Ann Intern Med. 1996:124:497-504.

13. Degner LF, Sloan JA. Decision making during serious illness: what role do patients really want to play? J Clin Epidemiol. 1992;45:941-950

14. Kaplan SH, Gandek B, Greenfield S, Rogers W, Ware JE. Patient and visit characteristics related to physicians' participatory decisionmaking style. Results from the Medical Outcomes Study. Med Care. 1995:33:1176-1187

15. O’Dell KJ, Volk RJ, Cass AR, Spann SJ. Screening for prostate cancer with the prostate-specific antigen test: are patients making informed decisions? J Fam Pract. 1999;48:682-688.

16. Chan EC, Vernon SW, O'Donnell FT, et al. Informed consent for cancer screening with prostate-specific antigen: how well are men getting the message? Am J Public Health. 2003;93:779-785.

17. Federman DG, Goyal S, Kamina A, Peduzzi P, Concato J. Informed consent for PSA screening: does it happen? Eff Clin Pract. 1999;2:152-157.

18. National health interview survey, 2000. Machine readable data file and documentation. Hyattsville, Md: National Center for Health Statistics; 2002.

19. Stata Statistical Software [computer program]. Version Release 7.0. College Station, TX: Stata Corporation; 2001.

20. McFall SL. Race/ethnicity and use of prostate specific antigen tests in U.S. men: The University of Texas Health Science Center-Houston School of Public Health; 2005.

21. Dunn AS, Shridharani KV, Lou W, Bernstein J, Horowitz CR. Physician-patient discussions of controversial cancer screening tests. Am J Prev Med. 2001;20:130-134. 